\title{
Uma Contribuição ao Processo de Soldagem Plasma de Arco Transferido (PTA) para Posições Forçadas
}

\section{(A contribution to the plasma transferred arc welding process (PTA) in flat, horizontal and overhead positions)}

\author{
Victor Vergara Díaz', Jair Carlos Dutra², Ana Sofia S.C. M. D’Oliveira ${ }^{3}$ \\ ${ }^{1}$ Universidad de Antofagasta, Departamento de Ingeniería Mecánica, Antofagasta, Chile, vvergara@uantof.cl \\ ${ }^{2}$ Universidade Federal de Santa Catarina, Departamento de Engenharia Mecânica, Florianópolis, Santa Catarina, Brasil \\ ${ }^{3}$ Universidade Federal do Paraná, Departamento de Engenharia Mecânica, Curitiba, Paraná, Brasil
}

\begin{abstract}
Resumo
Neste projeto foram realizados estudos do processo de soldagem plasma de arco transferido (PTA) com o objetivo de contribuir à soldagem em posições forçadas. A tocha de soldagem foi desenvolvida a partir de uma tocha plasma para keyhole, o que permite a utilização de dois modelos de bicos constritores de plasma com diferentes ângulos de convergência para a alimentação do pó, 30 e 60 graus de ângulo de convergência. Com isto abre-se uma nova perspectiva para revestimentos metálicos fora de posição plana e neste contexto se insere a recuperação por soldagem de partes erodidas por cavitação de turbinas hidráulicas. Com o objetivo de conhecer o comportamento do processo fora da posição foram conduzidos alguns experimentos com corrente contínua pulsada, utilizando-se a liga Stellite 6, e comparados com os resultados obtidos na posição horizontal e plana. A liga Stellite 6 vem sendo uma das mais utilizadas por apresentar uma excelente resistência ao desgaste por abrasão, erosão, impacto e cavitação. Foram avaliadas as características geométricas dos cordões, grau de diluição, dureza e microestrutura. Na posição horizontal e sobre-cabeça foram encontrados resultados inéditos, tornando o LABSOLDA pioneiro em revestimentos fora da posição plana neste processo de soldagem.
\end{abstract}

Palavras chave: Soldagem Plasma, Arco Transferido, Revestimentos, Stellite 6

\begin{abstract}
In this Project, besides of producing an equipment of plasma welding with injection of powder (PTA), studies were done with the purpose of contributing to the welding in flat, horizontal and overhead. The welding torch was developed starting from a Plasma torch for the keyhole. Furthermore, the adaptation proyect allows the use of two constrictor plasma nozzles with different convergency angles for powder feeding. For this proyect, two models were built, a nozzle with a $30^{\circ}$ angle and another one with a $60{ }^{\circ}$ convergency angle. With this, a new perspective is opened for metallic coverings out of a flat position and within this context it is inserted the recovery of the welding of eroded parts due to the cavitation of hydraulic turbines. With the purpose of knowing the behavior of the process out of position, some experiments were done with pulsed continue current by using the alloy of Stellite 6 and they were compared with the results obtained in the flat and horizontal position. The Stellite 6 alloy is being one of the most useful since it presents an excellent resistance to erode by abrasion, impact, erosion and cavitation. The geometric characteristics of the wires are evaluated, dilution degree, hardness and microestructure. In the horizontal position and overhead, the results found were unknown, making LABSOLDA the pioneer in recoverings outside the flat position in this welding process.
\end{abstract}

Key-words: Plasma welding, Transferred arc, hardfacing, Stellite 6

\section{Introdução}

Uma análise da literatura mostrou que os trabalhos que utilizam o processo PTA abordam, somente, a soldagem na posição plana, não apresentando procedimentos para a deposição em outras posições $[1,2,4]$. Ocorre que, para viabilizar a aplicação do processo PTA nas mais variadas aplicações na pratica, como por exemplo, na recuperação de pás de turbinas hidráulicas que sofreram erosão por cavitação, a identificação de resultados em outras posições é uma condição fundamental.

(Recebido em 05/03/2010; Texto final em 17/03/2011).

Artigo originalmente publicado no CONSOLDA 2009,
O processo se apresenta adequado para ser aplicado em revestimentos porque produz valores de diluição da ordem de 5 a $10 \%$ [1], muito inferior ao que se obtém com outros processos de soldagem a arco (da ordem de 20 a $25 \%$ ). Outras vantagens do processo de soldagem PTA estão relacionadas com a baixa distorção, pequena zona afetada pelo calor e microestrutura refinada $[2,3]$.

Neste processo são utilizados três fluxos de gases [4]: Como gás de plasma é utilizado um gás inerte, que é forçado a passar através do orifício do bico constritor, onde o eletrodo é fixado concentricamente. $\mathrm{O}$ gás de proteção, passa por um bocal externo, concêntrico ao bico constritor, atuando, efetivamente na proteção da solda contra a contaminação pelo ar atmosférico (pode ser ativo ou inerte). O gás de arraste ou de transporte é utilizado para carrear o material consumível até o bico constritor permitindo a entrada em forma convergente no arco plasma. $\mathrm{O}$ 
gás geralmente utilizado é argônio.

Para estabelecer a abertura do arco usa-se um ignitor eletrônico, devido a que o eletrodo de tungstênio está no interior do bico constritor da tocha de soldagem, então torna-se difícil a abertura do arco por contato. Usa-se um circuito que gera uma alta tensão em alta freqüência, para produzir a ionização da região situada entre a ponta do eletrodo e o bico constritor. Quando isto ocorre, abre-se um pequeno arco entre o eletrodo de tungstênio e o bico constritor, denominado de arco não transferido (chamado também de arco piloto) [4].

Oliveira [5] relata que o jato de plasma gerado pelo arco não transferido, em contato com o substrato, se torna uma espécie de condutor elétrico conectando-o ao eletrodo de tungstênio. Desta forma, quando a fonte de energia é acionada, já existe um caminho preferencial de gás ionizado e condutor de eletricidade, facilitando a abertura do arco transferido entre o eletrodo e o substrato.

O compromisso entre as variáveis corrente de soldagem, vazão de gás (gás de proteção, gás de plasma, gás de transporte), velocidade de soldagem, distância bico-peça, recuo do eletrodo e velocidade de soldagem, determinará a qualidade da solda.

A distância entre a ponta do eletrodo e a face externa do bico constritor é chamada de recuo do eletrodo. Normalmente, os valores para ajuste de recuo do eletrodo variam conforme o modelo da tocha de soldagem. Por exemplo, a tocha de soldagem PWM-300, fabricada pela Thermal Dynamics Corporation, possui uma faixa de ajuste para o recuo do eletrodo que varia de 0,8 a $2,4 \mathrm{~mm}$.

À medida que se reduz o recuo do eletrodo, a largura do cordão aumenta e são obtidos cordões com menor profundidade de penetração. Esta variação nas características geométricas do cordão de solda se deve à redução do efeito de constrição, produzindo uma maior área de incidência do arco sobre o substrato.

O efeito do ângulo de afiação da ponta do eletrodo de tungstênio foi estudado por Takano [6] concluindo que a afiação do eletrodo não afeta as características avaliadas na dureza dos revestimentos, apresentando um leve efeito sobre o perfil de penetração.

O bico constritor é fabricado de cobre e apresenta um orifício central pelo qual o arco e o volume de gás de plasma passam. Combinações entre valores do diâmetro do orifício constritor e de recuo do eletrodo estabelecem o grau de constrição do arco. Menor diâmetro do orifício constritor e maior recuo do eletrodo resultam em um maior grau de constrição, provocando um arco mais concentrado. Isto implica numa menor relação largura/ penetração do cordão de solda. Por outro lado, um diâmetro maior do orifício constritor e um menor recuo do eletrodo resultam em um arco de menor densidade de energia e, desta forma, um aumento na relação largura/penetração do cordão de solda.

Takano [6] estudou o efeito do diâmetro do bico constritor e relata que o efeito de constrição do bocal é função da intensidade de corrente empregada, sendo mais significativo para maiores intensidades de corrente, onde afeta a penetração e aspecto superficial do revestimento.
A distância da face externa do bico constritor até o substrato é a chamada de distância bico-peça [7]. Deuis et al. [8] relatam que para poder obter um bom rendimento de deposição, a distância bico-peça não deve ser maior do que 10 a $15 \mathrm{~mm}$. Para valores excessivos resulta na perda da eficácia na proteção gasosa. No trabalho de Hallen et al. [9] são mostrados os resultados em relação à distância bico-peça para 15 e $20 \mathrm{~mm}$, demonstrando que a medida que aumenta a distância bico-peça o grau de diluição diminui.

Como pode ser observado, são muitas as variáveis que devem ser controladas no processo de Soldagem Plasma de Arco Transferido (PTA), para realizar soldas livres de descontinuidades. Outra consideração que deve ser feita é com relação à modulação da corrente de soldagem. O processo pode utilizar a corrente continua constante ou a corrente continua pulsada. A utilização da corrente contínua pulsada, apresenta como vantagem sobre a corrente contínua constante a possibilidade de um melhor controle da poça de fusão e, conseqüentemente, sua aplicação em todas as posições de soldagem. Pesquisas têm sido desenvolvidas por D'Oliveira [4] e Vergara [11], com o intuito de avaliar as vantagens da aplicação de corrente contínua pulsada em relação à soldagem em corrente contínua convencional.

Com o objetivo de conhecer o comportamento do processo fora da posição foram conduzidos alguns experimentos com corrente contínua pulsada, utilizando-se a liga comercialmente conhecida como Stellite 6, e comparados com os resultados obtidos na posição plana. São avaliadas as características geométricas dos cordões, grau de diluição, dureza e microestrutura.

\section{Materiais e métodos}

\subsection{Bancada de ensaios}

A máquina de solda utilizada foi uma fonte de soldagem multiprocesso transistorizada, dotada de interface para conexão com microcomputador. Por intermédio de um software bastante versátil, é realizada abertura do arco e controle das variáveis de soldagem. Dos três circuitos de gás, o que foi dado maior atenção foi o gás de plasma pela sua grande relevância na qualidade dos depósitos. Por isso, foi usado não simplesmente um medidor de vazão, mas sim um controlador de vazão mássica. O controle é realizado eletronicamente e o sinal de regulagem é uma tensão de referência. $\mathrm{O}$ gás de proteção foi simplesmente monitorado por fluxômetro eletrônico, porém volumétricos. Para o deslocamento da tocha de soldagem foi utilizado um dispositivo eletrônico denominado de TARTÍLOPE. O componente do sistema, que foi integralmente projetado para este desenvolvimento específico, foi o dispositivo de alimentação de pó, que funciona com a combinação de um parafuso sem fim e de um fluxo de gás como mecanismos para carrear o pó. A tocha de soldagem foi um desenvolvimento a partir de uma tocha plasma para keyhole. A grande vantagem está no aspecto multiprocesso da mesma, que permite, ora trabalhar com o plasma com pó e ora que com plasma convencional. Além disso, o projeto de adaptação permite a utilização de bicos constritores de plasma 
com diferentes ângulos de convergência para a alimentação do pó. Para este projeto foram fabricados dois modelos, um com 30 e outro com 60 graus de ângulo de convergência. $O$ diâmetro do orifício de constrição da tocha é de $4,8 \mathrm{~mm}$.

Neste trabalho foi utilizado argônio com pureza de 99,99 \% para os gases de plasma, proteção e de transporte. Utilizou-se um eletrodo de tungstênio com $2 \%$ de óxido de tório (EWTh2) com diâmetro de $4,8 \mathrm{~mm}$. O ângulo da ponta do eletrodo foi mantido em $30^{\circ}$ para todos os experimentos.

\subsection{Bicos constritores de plasma com diferentes ângulos de convergência para a alimentação do pó.}

A configuração do bico constritor desenvolvida neste trabalho inclui dois conduítes de passagem de gás de arraste, cujo objetivo é de alimentar com pó o arco plasma, em forma convergente. Os ângulos de convergência dos canais de passagem do gás de arraste e pó (Figura 1) foram escolhidos em função do critério adotado pela referencia [5], usando arame como material de adição. O autor testou dois pontos de intersecção arame/arco. O primeiro ponto, o arame é direcionado de modo a interceptar o arco a meia altura da distância bico-peça e o segundo ponto de intersecção, corresponde a um ponto da superfície da poça fundida.

A Figura 1 mostra o corte transversal dos bicos constritores. O bico constritor de $30^{\circ}$, permite a entrada de pó no arco plasma bem próximo da face externa do bico constritor, ou seja, a uma distância de $3,2 \mathrm{~mm}$. Por outro lado, o bico constritor de $60^{\circ}$ permite a entrada de pó diretamente na poça fundida, quando é utilizada uma distância bico-peça de $10 \mathrm{~mm}$. O critério principal na avaliação do ângulo de convergência do bico constritor é a qualidade do depósito.

\subsection{Posição e sentido de deslocamento da tocha.}

A Figura 2 mostra a posição e sentido de deslocamento da tocha que correspondem á posiçao plana, horizontal e sobrecabeça, respectivamente. O fluxo do gás de arraste e pó estão no mesmo plano da direção de soldagem, ou seja, os dois furos que permitem a passagem do gás de arraste, estão alinhados em relação à direção de soldagem.

\subsection{Caracterização}

Depósitos da liga Stellite 6 atomizada, Figura 3, foram processados sobre chapas de aço carbono da classe ABNT 1020, cortadas nas dimensões de $12,5 \times 60 \times 235 \mathrm{~mm}$ e esmerilhadas para remoção da camada de óxido. Utilizou-se a corrente continua pulsada, conforme apresentado na Tabela 1. A análise química dos diferentes materiais foi realizada através da técnica de espectrometria de emissão ótica e está apresentada nas Tabelas 2 e 3 .

\section{Bico-Constritor}

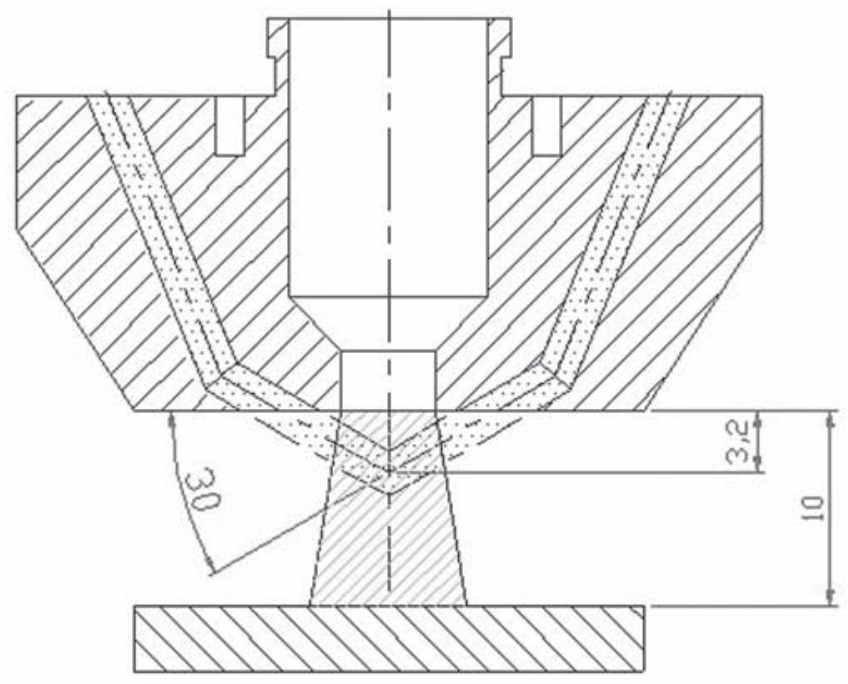

Substrato
Bico-Constritor

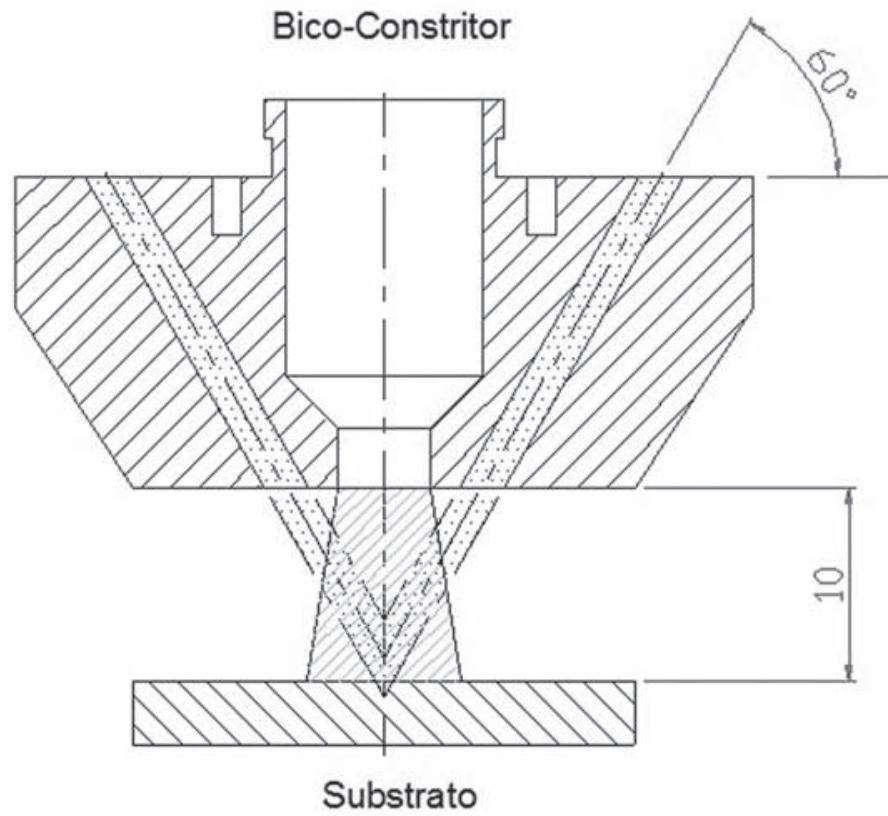

(a) Bico de $30^{\circ}$

(b) Bico de $60^{\circ}$

Figura 1. Corte transversal dos bicos constritores mostrando a entrada do fluxo de pó no arco plasma. a) Meia altura, b) Diretamente na poça de fusão 


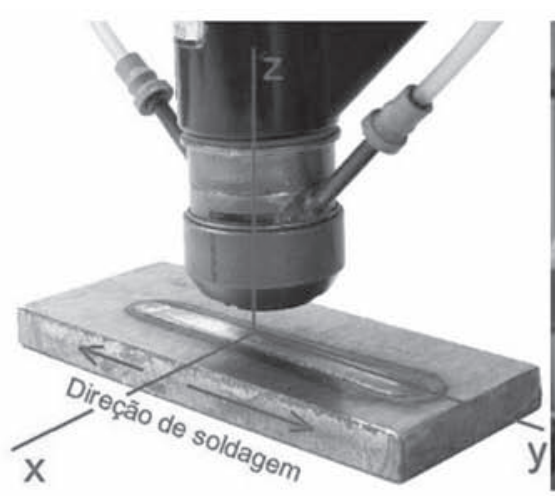

Posição plana

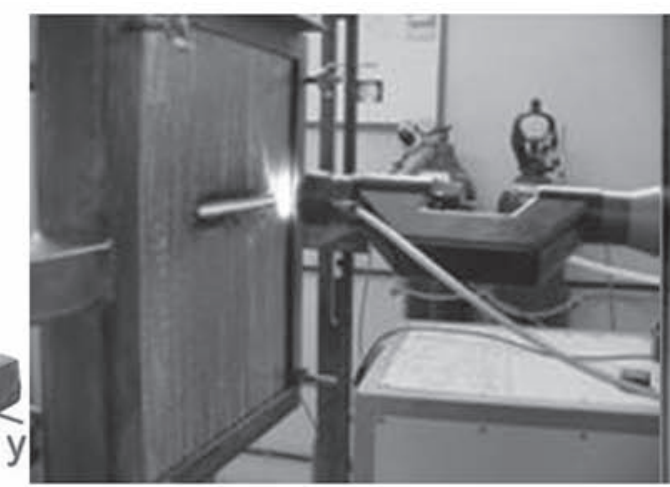

Posição horizontal

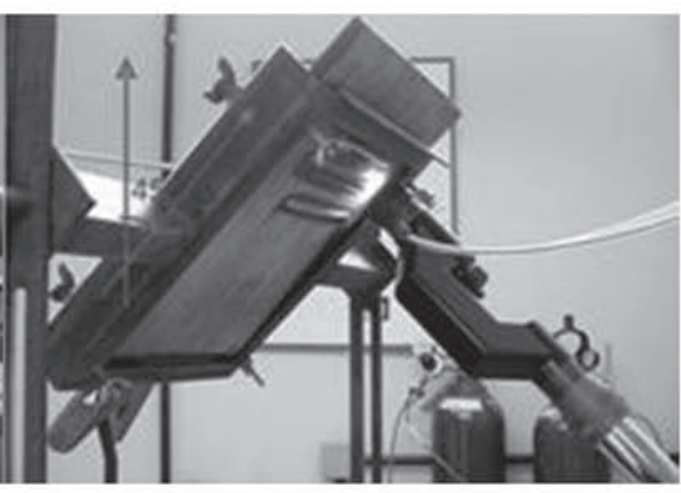

Posição sobre-cabeça

Figura 2. Fotos ilustrativas da posição da tocha para soldagem plana, horizontal e sobre-cabeça

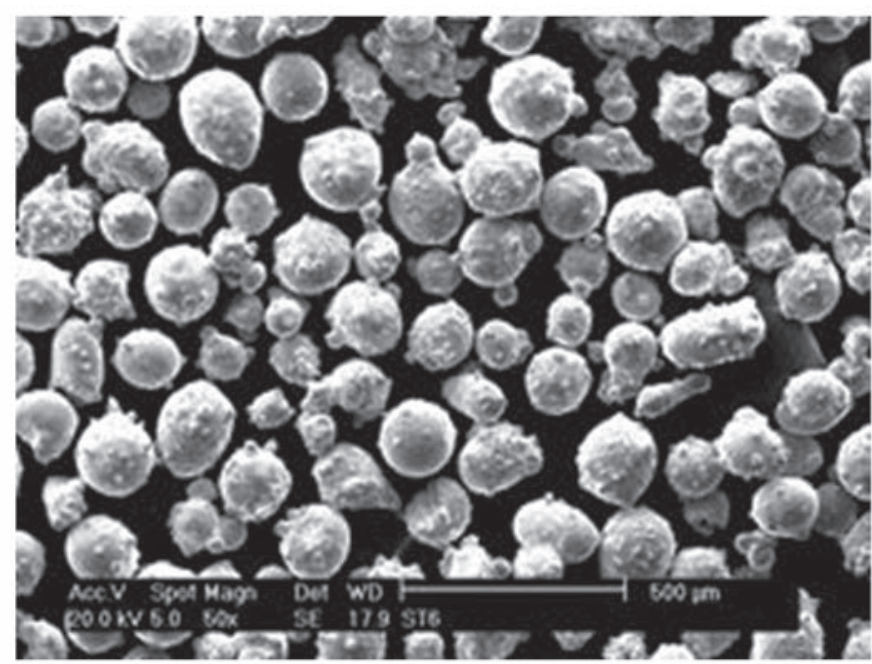

Figura 3. Morfologia do pó depositado pelo processo PTA (Stellite 6)
Tabela 1. Variáveis e parâmetros de soldagem

\begin{tabular}{c|c|c}
\hline Variáveis & Unidade & Valor \\
\hline Corrente média de soldagem & $\mathrm{Im}(\mathrm{A})$ & 160 \\
\hline Corrente de pulso & $\mathrm{Ip}(\mathrm{A})$ & 200 \\
\hline Corrente de base & $\mathrm{Ib}(\mathrm{A})$ & 120 \\
\hline Freqüência de pulsação & $\mathrm{f}(\mathrm{Hz})$ & 5 \\
\hline Tempo de pulso & $\mathrm{s}$ & 0,1 \\
\hline Tempo de base & $\mathrm{s}$ & 0,1 \\
\hline Velocidade de soldagem & $\mathrm{Vs}(\mathrm{cm} / \mathrm{min})$ & 16 \\
\hline Gás de plasma & $\mathrm{VGP}(1 / \mathrm{min})$ & 2,4 \\
\hline Gás de proteção & $\mathrm{GPr}(1 / \mathrm{min})$ & 10 \\
\hline Gás de transporte & $\mathrm{GTr}(1 / \mathrm{min})$ & 2 \\
\hline Taxa de deposição & $\mathrm{Tx}(\mathrm{kg} / \mathrm{h})$ & 1,4 \\
\hline $\begin{array}{c}\text { Diâmetro do bico constritor/ } \\
\text { ângulo de convergência }\end{array}$ & $\mathrm{d}(\mathrm{mm}) /\left({ }^{\circ}\right)$ & $4,8 / 30-4,8 / 60$ \\
\hline Distância bico-peça & $\mathrm{DBP}(\mathrm{mm})$ & 10 \\
\hline
\end{tabular}

Recuo

$\mathrm{Rc}(\mathrm{mm})$

Tabela 2. Composição química substrato aço baixo carbono

\begin{tabular}{c|c|c|c|c|c|c|c|c}
\hline $\mathrm{C}$ & $\mathrm{Si}$ & $\mathrm{Mn}$ & $\mathrm{P}$ & $\mathrm{S}$ & $\mathrm{Cr}$ & $\mathrm{Mo}$ & $\mathrm{Ni}$ & $\mathrm{Al}$ \\
\hline 0,11 & 0,22 & 0,74 & 0,021 & 0,008 & 0,027 & 0,024 & 0,011 & 0,06 \\
\hline $\mathrm{Co}$ & $\mathrm{Cu}$ & $\mathrm{Nb}$ & $\mathrm{Ti}$ & $\mathrm{V}$ & $\mathrm{W}$ & $\mathrm{Sn}$ & $\mathrm{Fe}$ & \\
\hline- & 0,016 & - & - & 0,015 & 0,026 & 0,065 & 98,6 & \\
\hline
\end{tabular}

Espessura : $12,7 \mathrm{~mm}$

Tabela 3. Composição química material de aporte Stellite 6 na forma de pó (BT-906)

\begin{tabular}{c|c|c|c|c|c|c|c|c}
\hline $\mathrm{C}$ & $\mathrm{Si}$ & $\mathrm{Mn}$ & $\mathrm{Cr}$ & $\mathrm{Mo}$ & $\mathrm{Ni}$ & $\mathrm{Co}$ & $\mathrm{W}$ & $\mathrm{Fe}$ \\
\hline 1,32 & 1,30 & 0,028 & 30,01 & 0,24 & 2,45 & $\mathrm{Bal}$ & 5,21 & 2,05 \\
\hline
\end{tabular}


Dureza: 38-47 Rc; Granulometria: 45 a 150 15 ; Densidade: $8,3 \mathrm{~g} / \mathrm{cm}^{3}$

Inicialmente os depósitos foram submetidos a inspeção visual quanto a presença de defeitos de soldagem, o grau de diluição foi determinado pelo método das áreas em uma macrografia da seção transversal dos depósitos, ataque com nital 6\%. Perfis de microdureza Vickers, com carga de $500 \mathrm{~g}$, permitiram avaliar a uniformidade dos cordões na seção transversal, seguindo neste procedimento a norma ABNT6672/81. O levantamento dos perfis de microdureza, média de três medidas, foi feito no centro dos cordões e na região de sobreposição dos mesmos. A Figura 4 mostra um esquema da seção transversal do cordão, indicando a localização das impressões de microdureza. Para avaliação da microestrutura por microscopia ótica, a preparação da seção transversal seguiu procedimentos padrão sendo a microestrutura revelada após ataque eletrolítico com ácido oxálico.

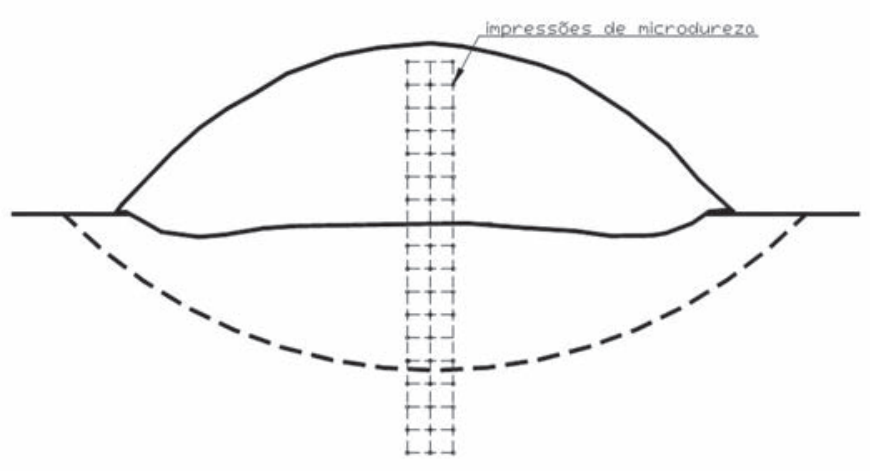

Figura 4. Esquema da secção transversal do cordão, indicando a localização das impressões de microdureza

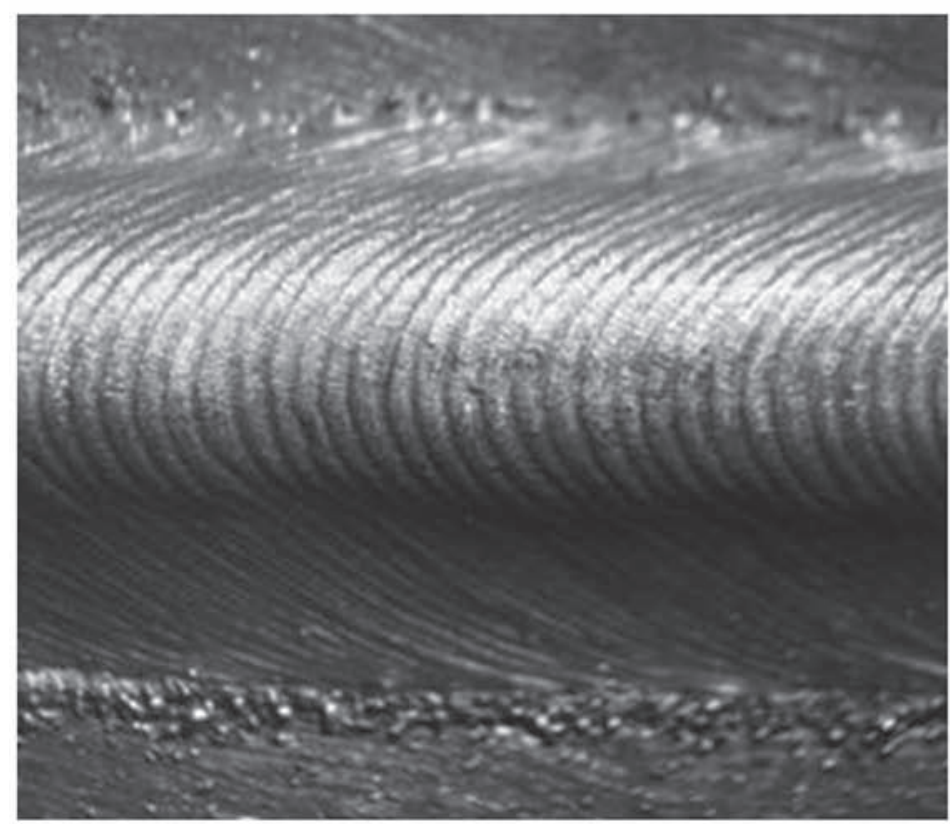

(a)

\section{Resultados e discussão}

\subsection{Desempenho do tipo de bico constritor}

Antes de iniciar o estudo, foi verificado o desempenho do tipo de bico constritor. A Figura 5a e 5b mostram as diferenças do aspecto superficial dos depósitos sobre-cabeça para os dois tipos de bicos constritores projetados. Observe-se que quando é empregado o bico constritor de $30^{\circ}$, fica pó aderido nas laterais dos depósitos, Figura 4a, fato que não é observado no bico constritor de $60^{\circ}$, Figura $5 \mathrm{~b}$. Resultados semelhantes foram encontrados na posição plana e horizontal.

\subsection{Influencia da variação na vazão de gás de arraste.}

A influência da variação na vazão do gás de arraste foi verificada neste trabalho, utilizando-se vazões do gás de arraste de 2,4 e 6 1/min. A figura 6 mostra o aspecto superficial dos cordões onde é possível observar o aparecimento de escamas típico da aplicação da corrente pulsada. As fotografias revelam variação no aspecto geométrico do cordão devido ao aumento da vazão de gás de arraste. Os resultados são críticos para uma vazão de $61 / \mathrm{min}$ já que se observam salpicos perto das laterais do cordão de solda. A Figura 7 mostra a secção transversal dos depósitos para três níveis de vazão de gás de arraste. Foi observado que para uma vazão de gás de arraste de $61 / \mathrm{min}$, ocorreu falta de fusão em as laterais do cordão, Figura 7c. Em relação à diluição, verificouse que se consegue um valor baixo quando é utilizado o maior valor do gás de arraste. Figura 7.

Os resultados divergem dos obtidos em estudos anteriores [10], que encontraram que, para uma mesma corrente media, o grau de diluição aumenta quando se incrementa a vazão de gás de arraste.

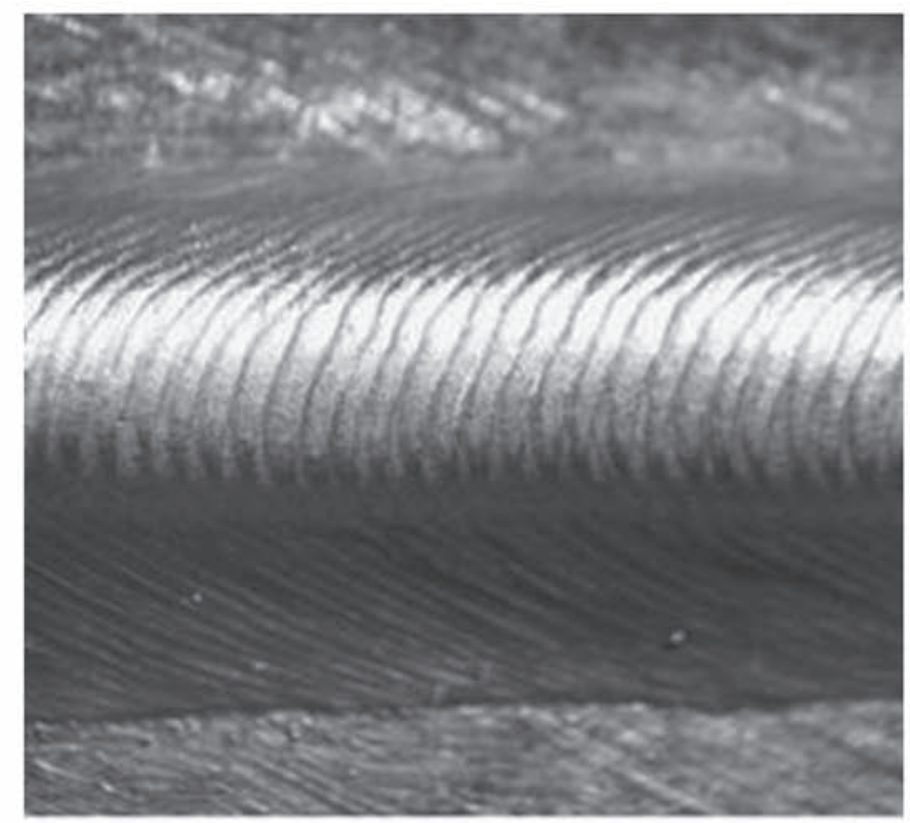

(b)

Figura 5. Aspecto superficial para (a) o bico constritor de $30^{\circ}$ e (b) Para o bico constritor de $60^{\circ}$ 


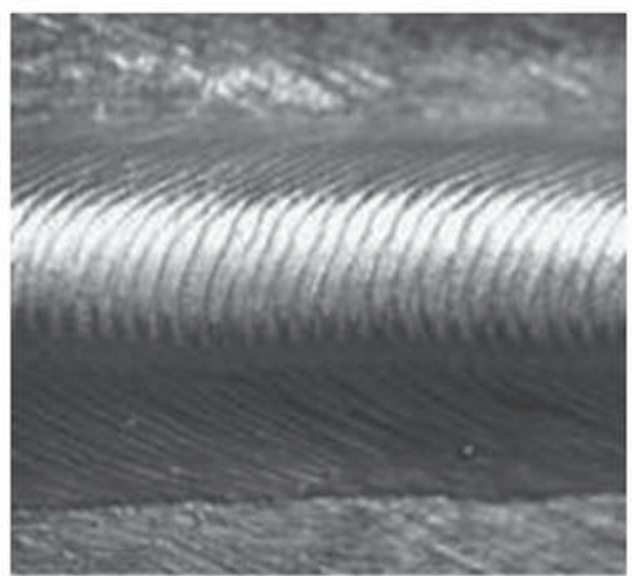

Gás de arraste $=21 / \mathrm{min}$

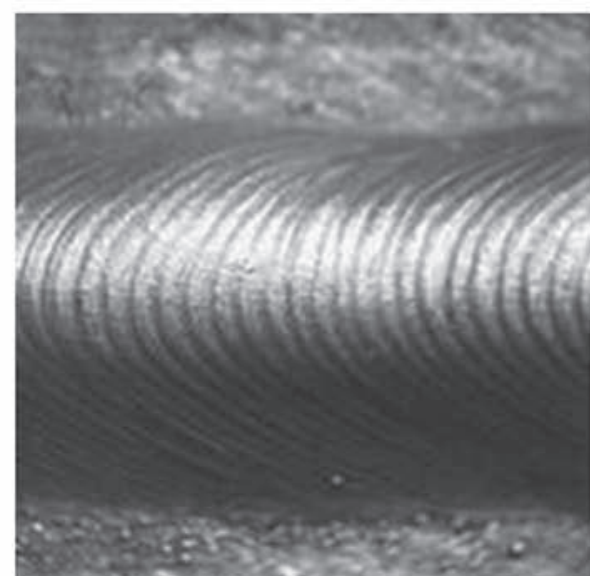

Gás de arraste $=41 / \mathrm{min}$

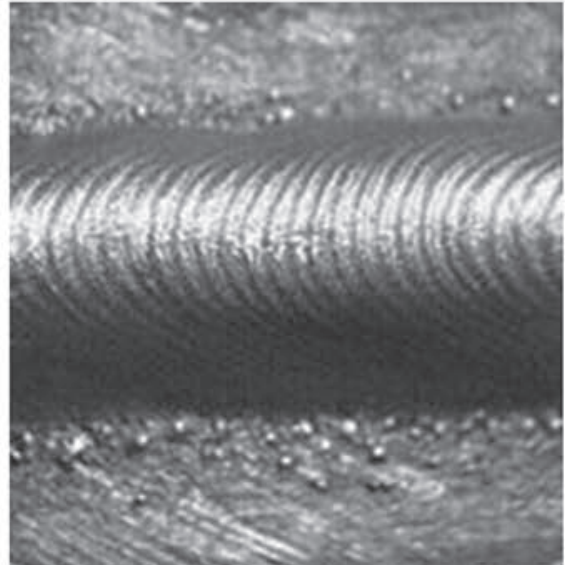

Gás de arraste $=61 / \mathrm{min}$

Figura 6. Aspecto superficial para três níveis de vazão de gás de arraste

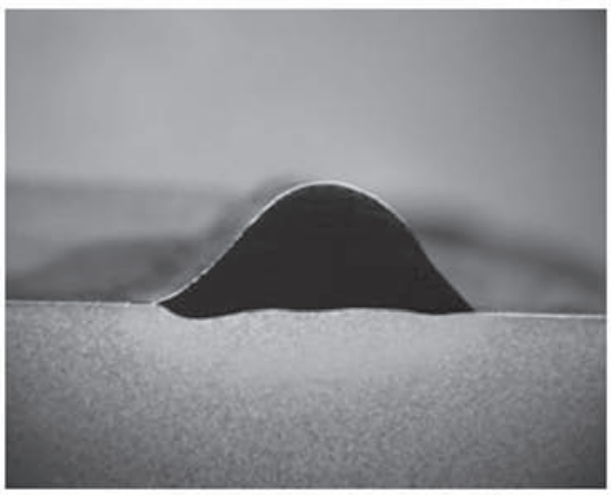

(a) Diluição $=4.3 \%$

Gás de arraste: $21 / \mathrm{min}$

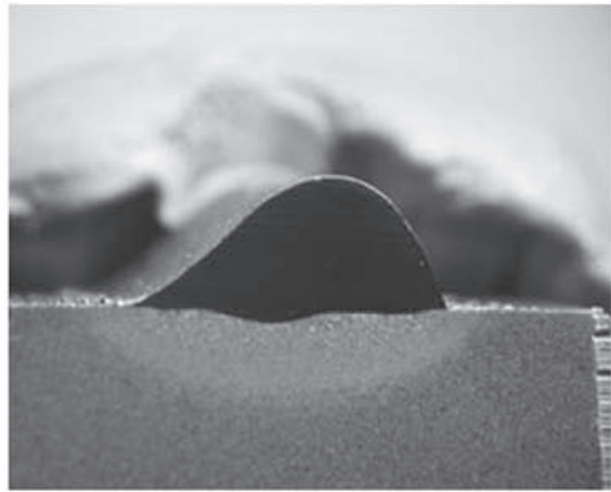

(b)Diluição $=7.5 \%$

Gás de arraste: $41 / \mathrm{min}$

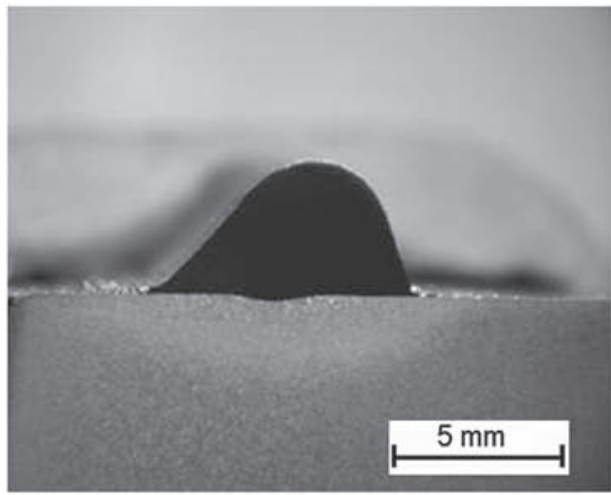

(c) Diluição $=1.6 \%$

Gás de arraste: $61 / \mathrm{min}$

Figura 7. Secção transversal dos depósitos para três níveis de vazão de gás de arraste

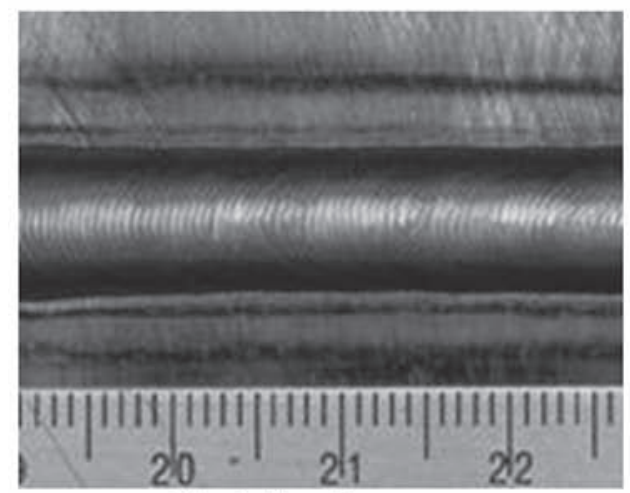

Posição plana

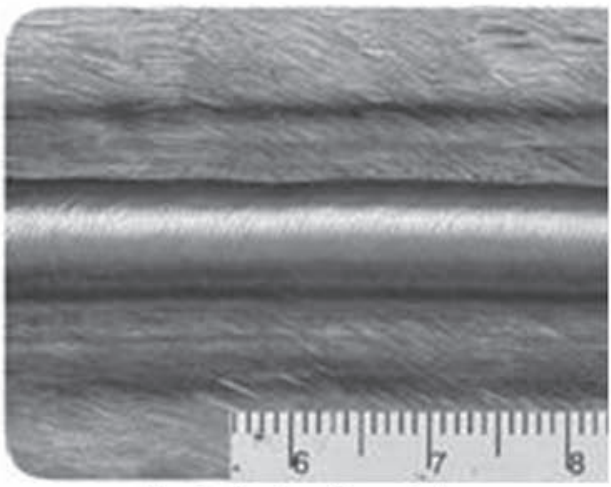

Posição horizontal

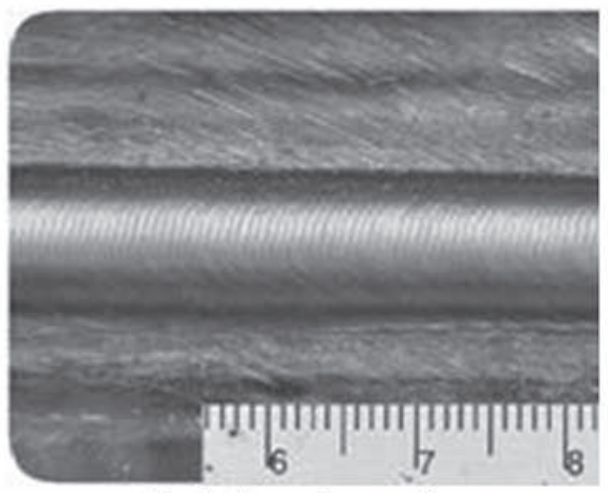

Posição sobre-cabeça

Figura 8. Aspecto superficial do cordão na posição plana, horizontal e sobre-cabeça 


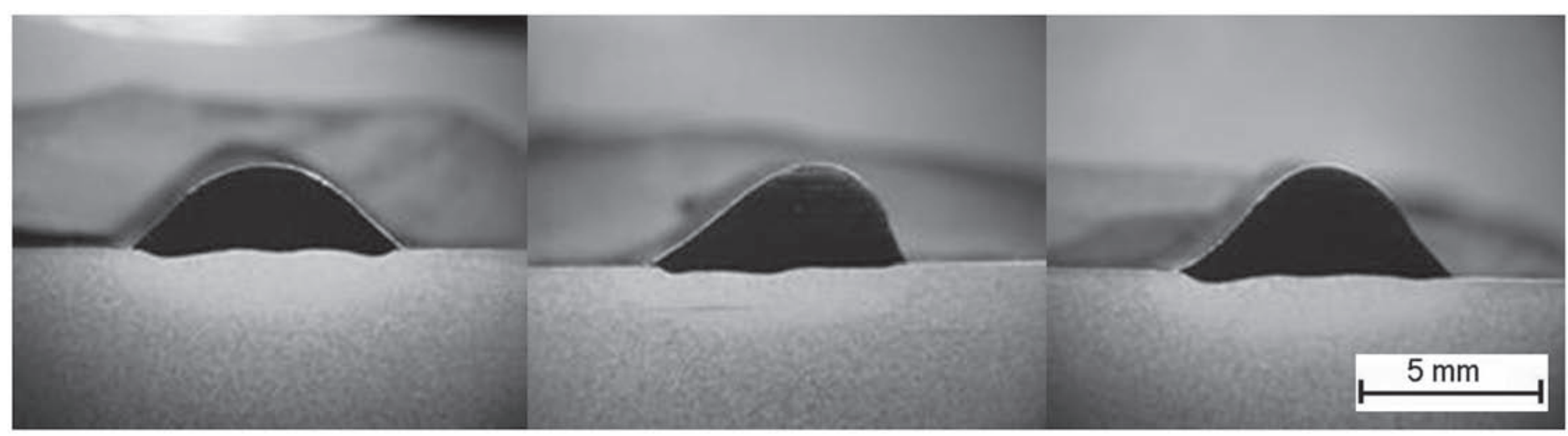

Posição plana

Posição horizontal

Posição sobre-cabeça

Figura 9. Perfil de penetração do cordão na posição plana, horizontal e sobre-cabeça

Devido a estes fatos, optou-se por trabalhar com um bico de $60^{\circ}$ e com uma vazão de gás de arraste de $21 / \mathrm{min}$. A Figura 8 mostra o aspecto superficial dos cordões obtidos na posição plana, horizontal e sobre cabeça, respectivamente. A Figura 9 mostra a secção transversal dos cordões, aonde é possível observar, que o cordão realizado na posição plana, Figura 9a, apresenta uma diferença significativa na geometria da interface entre o revestimento e o material de base, em relação às outras posições de soldagem, Figuras 9b e 9c. Observe-se na Figura 9a, que a maior penetração está localizada nas laterais do cordão de solda e não na região central do perfil do cordão como é possível observar nos processos convencionais de soldagem. É uma observação que deve ser considerada no analise das curvas de dureza, devido a que o perfil de microdureza é realizado na região central da secção transversal do cordão, segundo o procedimento da Figura 4 correspondente ao ítem 2.4 de materiais e métodos.

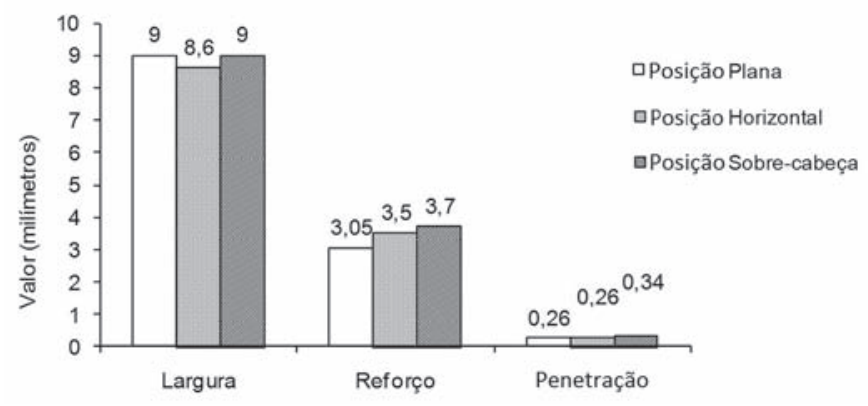

Figura 10. Parâmetros geométricos dos cordões
A análise da Figura 10, e apoiada com a análise de variância das Tabelas 4 à 6 indica que, de uma forma geral, a posição de soldagem afeta significativamente na largura, reforço e penetração. Pela análise da Figura 10 e apoiada com a análise de variância da Tabela 5, percebe-se um efeito significativo no tamanho do reforço, apresentando-se os maiores valores na posição sobre cabeça e horizontal, devido a que nesta posição a poça fundida é afetada fortemente pelo efeito da gravidade. A análise da Figura 11 e apoiada com a análise de variância da Tabela 7 mostra que a posição de soldagem afeta significativamente sobre o grau de diluição dos depósitos, entretanto o processo se apresenta adequado porque produz valores de diluição da ordem de 5,5 a $6,4 \%$.

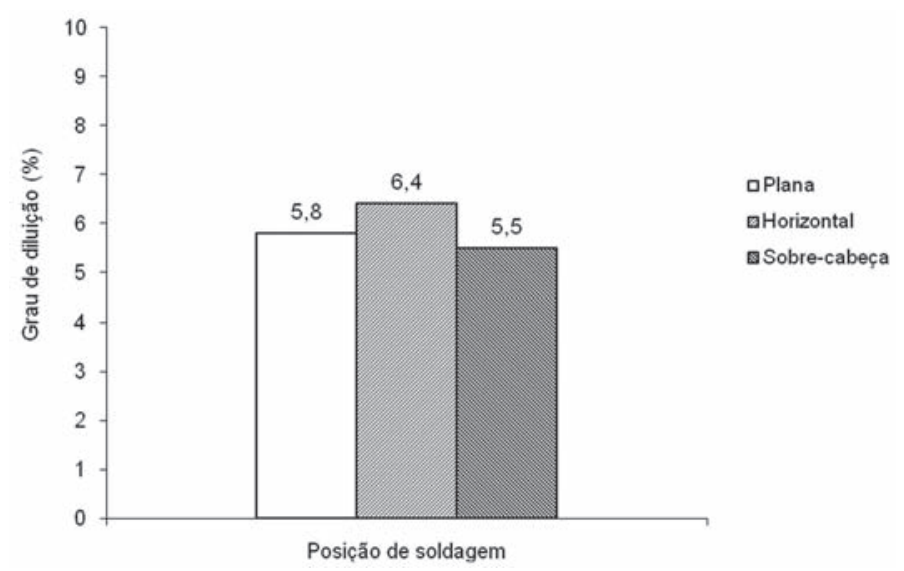

Figura 11. Efeito da posição de soldagem sobre o grau de diluição 
Tabela 4. Resultados de análise de variância para a largura

\begin{tabular}{cccccc}
\hline Fonte da variação & Soma dos quadrados & Graus de Liberdade & Média dos quadrados & Fobservado & F crítico \\
\hline Posição de soldagem & 0,901 & 2 & 0,4505 & $79,035>$ & 3,89 \\
Residual & 0,068 & 12 & 0,0057 & & \\
Total & 0,969 & 14 & & \\
\hline
\end{tabular}

Obs.: Índice de significância $(\alpha)=5 \%$

Tabela 5. Resultados de análise de variância para o reforço

\begin{tabular}{|c|c|c|c|c|c|}
\hline Fonte da variação & Soma dos quadrados & Graus de Liberdade & Média dos quadrados & Fobservado & F crítico \\
\hline Posição de soldagem & 0,95 & 2 & 0,475 & $85,12>$ & 3,89 \\
\hline Residual & 0,067 & 12 & 0,00558 & & \\
\hline Total & 1,017 & 14 & & & \\
\hline
\end{tabular}

Obs.: Índice de significância $(\alpha)=5 \%$

Tabela 6. Resultados de análise de variância para a penetração

\begin{tabular}{|c|c|c|c|c|c|}
\hline Fonte da variação & Soma dos quadrados & $\begin{array}{l}\text { Graus de } \\
\text { Liberdade }\end{array}$ & Média dos quadrados & Fobservado & F crítico \\
\hline Posição de soldagem & 0,02297 & 2 & 0,0114867 & $229,7>$ & 3,89 \\
\hline Residual & 0,0006 & 12 & 0,00005 & & \\
\hline Total & 0,02357 & 14 & & & \\
\hline
\end{tabular}

Obs.: Índice de significância $(\alpha)=5 \%$

Tabela 7. Resultados de análise de variância para o grau de diluição

\begin{tabular}{cccccc}
\hline Fonte da variação & Soma dos quadrados & Graus de Liberdade & Média dos quadrados & Fobservado & F crítico \\
\hline Posição de soldagem & 2,223 & 2 & 1,1115 & $202,09>$ & 3,89 \\
Residual & 0,066 & 12 & 0,0055 & & \\
Total & 2,289 & 14 & & & \\
\hline
\end{tabular}

Obs.: Índice de significância $(\alpha)=5 \%$

Tabela 8 - Resultados de análise de variância para a dureza na região fundida

\begin{tabular}{cccccc}
\hline Fonte da variação & Soma dos quadrados & Graus de liberdade & Média dos quadrados & Fobservado & F crítico \\
\hline Posição de soldagem & 632,1267 & 2 & 316,0633 & $0,94<$ & 3,27 \\
Residual & 11781,49 & 35 & 336,614 & & \\
Total & 12413,62 & 37 & & & \\
\hline
\end{tabular}

Obs.: Índice de significância $(\alpha)=5 \%$ 
A Figura 12 mostra o perfil de microdureza para as três posições testadas. O deslocamento entre as curvas de dureza representa o tamanho do reforço e a penetração no centro do cordão. A análise da Figura 12, reforçada com a análise de variância da Tabela 8 indica que, de uma forma geral, a posição de soldagem não afeta significativamente na dureza da região fundida.

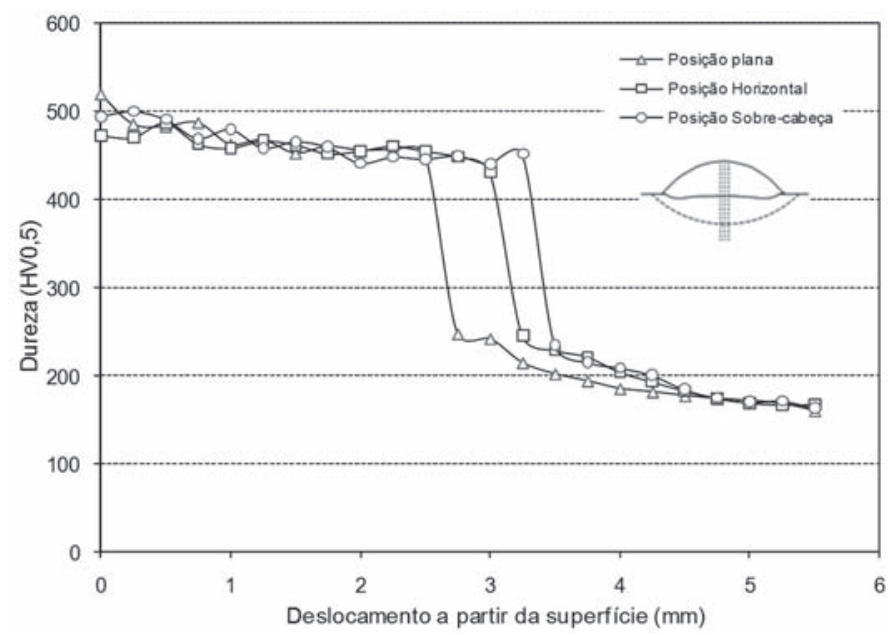

Figura 12. Dureza Vickers ao longo da secção transversal dos cordões para diferentes posições de soldagem
As figura 13 e 14 apresentam as microestruturas observadas junto a superfície externa do cordão e junto da linha de fusão, respectivamente. Observam-se microestruturas típicas de solidificação com a presença de dendritas e junto da linha de fusão observa-se uma frente plana de solidificação. Por outro lado é possível observar nas microestruturas, que a linha de fusão se apresenta com bastante nitidez. Resultados semelhantes foram encontrados por Santos (2003), envolvendo a liga Stellite 1. Com o apoio das figuras 13 y 14 , o estudo revela que a posição de deposição não apresenta impacto na microestrutura.

Uma vez analisados os cordões unitários, procedeu-se a realizar um revestimento na posição sobre cabeça a $45^{\circ}$ com o plano horizontal, empregando-se as mesmas condições de soldagem da Tabela 1. A Figura 15a apresenta o revestimento de uma camada depositado com 4 passes na posição sobrecabeça. Os cordões nesta posição de soldagem apresentaram boa sustentabilidade e bom acabamento superficial. A Figura 15b mostra a secção transversal. A região plana, na parte superior dos cordões de solda, é devido à remoção de material com o intuito de verificar planicidade.

Finalmente o teste de líquido penetrante, realizados sobre o revestimento, mostrou que não ocorreram defeitos como porosidades e falta de penetração.

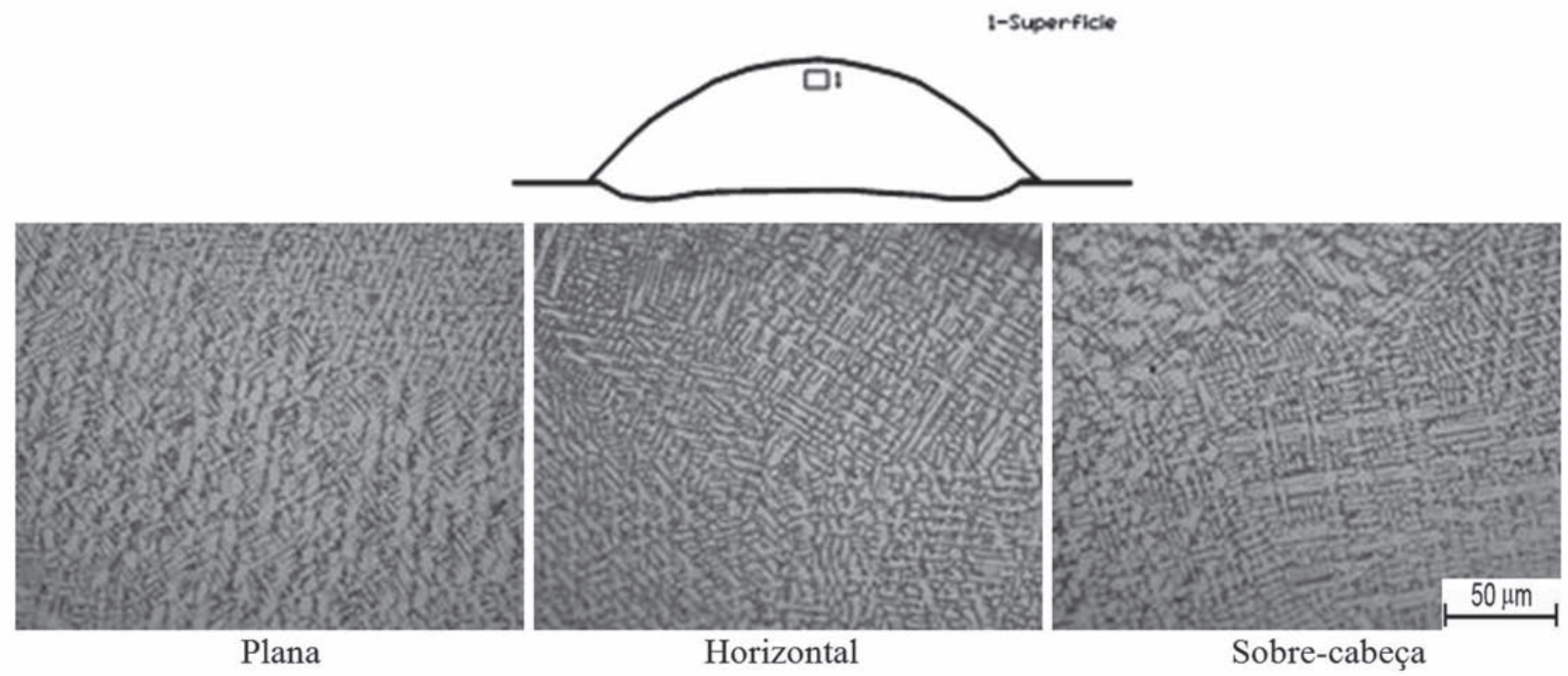

Figura 13. Micrografias das amostras de Stellite 6 junto à superfície. Posição plana/posição horizontal/posição sobre-cabeça 


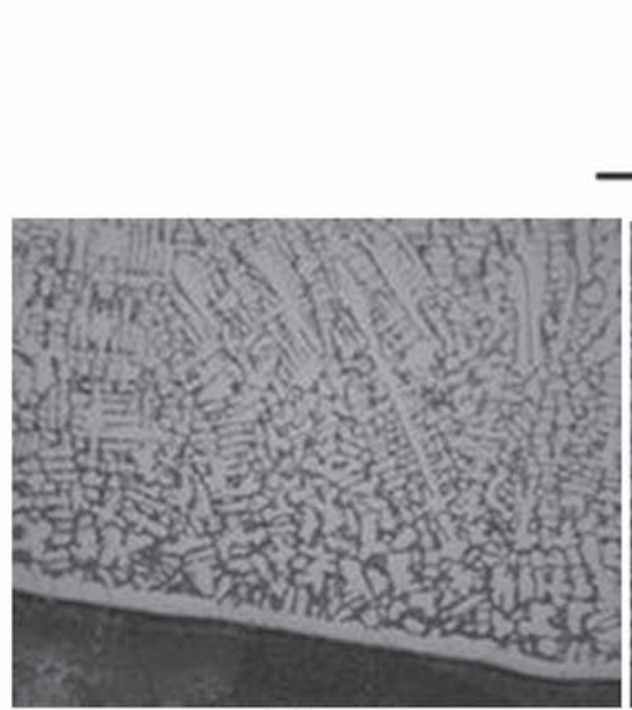

Plana

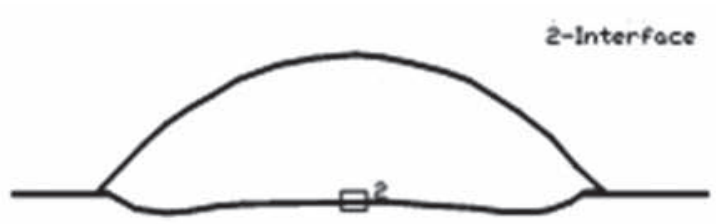

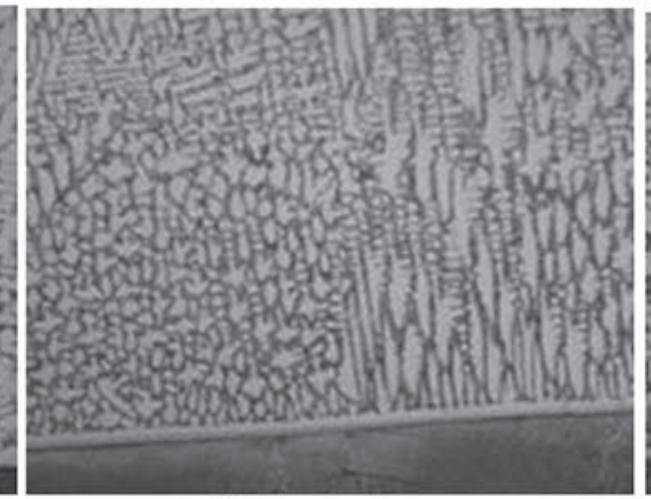

Horizontal

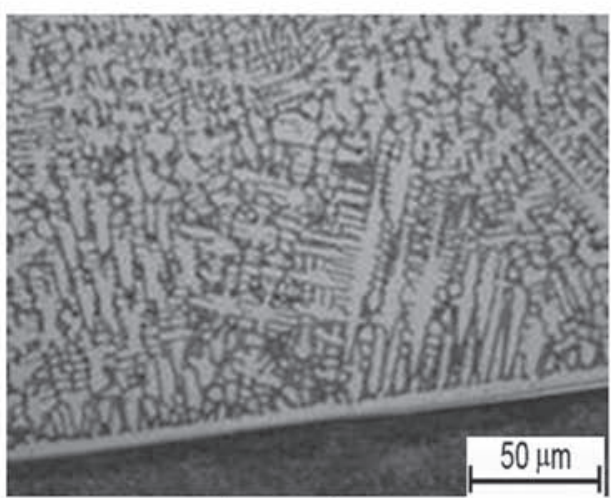

Sobre-cabeça

Figura 14. Micrografias da região de ligação substrato-depósito. Posição plana/posição horizontal/posição sobre-cabeça

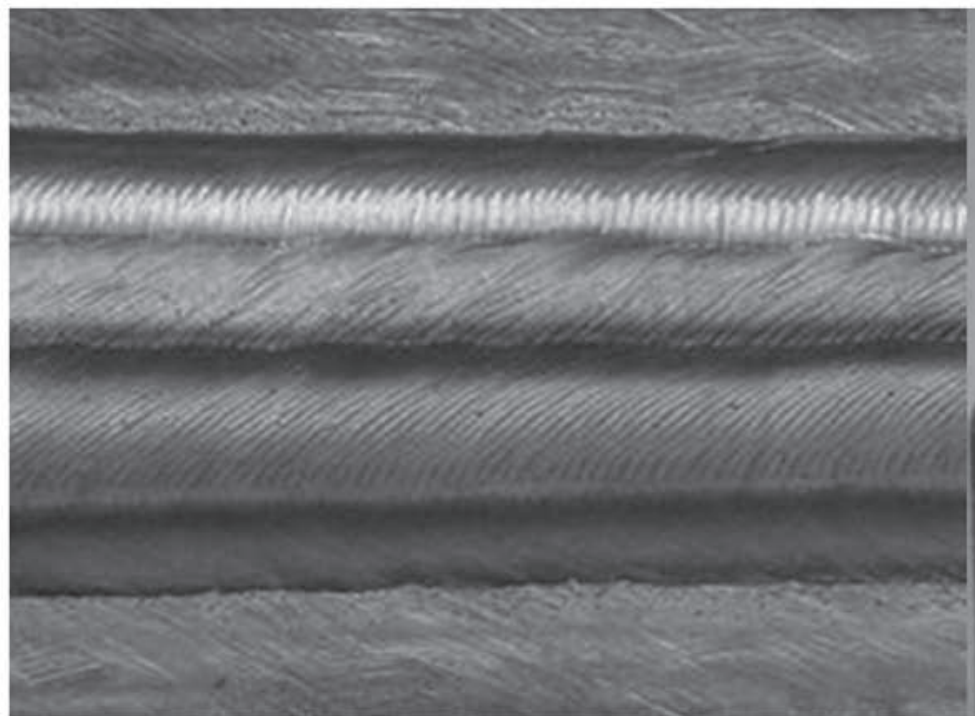

(a)

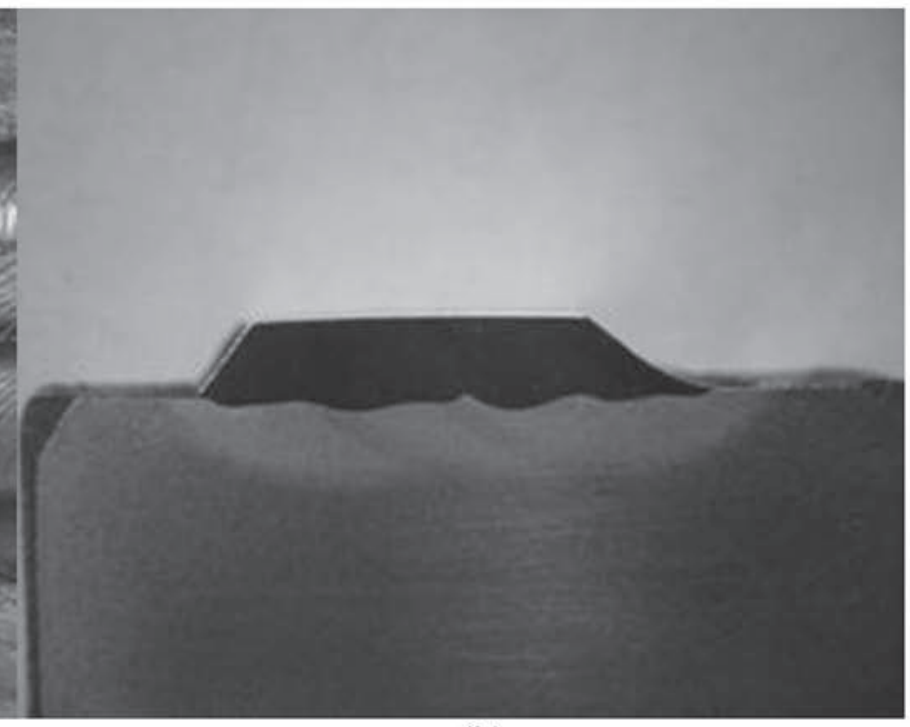

(b)

Figura 15. a) Uma camada. Aspecto superficial, b) Corte da secção transversal. Características do perfil de penetração e ZAC

\section{Conclusões}

Os resultados experimentais apresentados, dentro das condições utilizadas, permitem concluir que:

- O bico constrito de $60^{\circ}$ apresenta melhor desempenho frente ao bico constritor de $30^{\circ}$. Foi observado que quando é empregado o bico constritor de $30^{\circ}$, fica pó aderido nas laterais dos depósitos, fato que não é observado no bico constritor de $60^{\circ}$.

- Utilizando-se o bico constritor de $60^{\circ}$ para os ensaios na posição horizontal e sobre-cabeça, os cordões de soldagem apresentaram bom aspecto superficial e boa sustentabilidade.
- Frente ao posicionamento da tocha de soldagem a força de gravidade atua na poça fundida influenciando no formato do cordão de solda e nos parâmetros geométricos. Os maiores valores de reforço são conseguidos na posição sobre-cabeça devido ao efeito da força de gravidade.

- A dureza Vickers medida ao longo da secção transversal dos cordões, para diferentes posições de soldagem, não apresenta um efeito significativo.

- O processo de soldagem se apresenta adequado para ser aplicado em revestimentos metálicos fora da posição plana. $\mathrm{O}$ corte transversal do revestimento e ensaios com líquido penetrante permitiu observar ausência de defeitos tais como porosidade, falta de fusão e mordeduras. 


\section{Referências Bibliográficas}

[1] GATTO, A.; BASSOLI, E.; FORNARI, M. Plasma Transferred Arc deposition of powdered high performances alloys: process parameters optimisation as a function of alloy and geometrical configuration. Disponível em: $<\mathrm{http}: / / \mathrm{www}$. sciencedirect.com> Acesso em: Jun. 2009.

[2] ZHANG, L. et al. Effect of niobium on the microstructure and wear resistance of iron-based alloy coating produced by plasma cladding. Disponível em: $<\mathrm{http}: / / \mathrm{www}$.elsevier.com/ locate/msea> Acesso em: Nov. 2008.

[3] LIU, Y. F. et al. Microstructure and dry-sliding wear properties of TiC-reinforced composite coating prepared by plasma-transferred arc weld-surfacing process. Disponível em: $<$ http://www.elsevier.com/locate/msea $>$ Acesso em: Nov. 2008.

[4] D’Oliveira, A.S.C.M.; Paredes, R.S.C.; Santos, R.L.C. Pulsed current plasma transferred arc hardfacing. Disponível em: $<$ http://www.elsevier.com/locate/msea $>$ Acesso em: Nov. 2008.

[5] M. A. Oliveira. Estudo do processo plasma com alimentação automática de arame: 2001. 78p. Dissertação (Mestrado em Engenharia Mecânica)-Programa de Pós-Graduação em Engenharia Mecânica, UFSC, Florianópolis.

[6] TAKANO, E. H.; QUEIROZ, D.; D'OLIVEIRA, A.S.C.M., Avaliação dos parâmetros de processamento por PTA nas superfícies processadas, Disponível em: $<$ http://www.mecanica. ufu.br/revistasi/full/full_13_03_204.pdf $>$ Acesso em: Jan. 2010. [7] VERGARA, V. M. Inovação do equipamento e avaliação do processo plasma de arco transferido alimentado com pó (PTAP) para soldagem fora de posição: 2005. 174p.Tese (Doutorado em Engenharia Mecânica) - Programa de Pós-Graduação em Engenharia Mecânica, UFSC, Florianópolis.

[8] DEUIS, R. L.; YELluP, J. M.; SUBRAMANIAN, C. Metal-matrix composite coatings by PTA surfacing. Disponível em: $<$ http://www.sciencedirect.com> Acesso em: Jan. 2009.

[9] HALLEN, H.; LUGSCHEIDER, E.; AIT-MEKIDECHE, A. Plasma transferred arc surfacing with high deposition rates. In: Proceedings of conference on thermal spray coatings: properties. processes and applications, Pittsburgh, USA, 4-10 May 1991. ASM International; 1992. p. 537-9.

[10] RAVI BHARATH, R.; RAMANATHAN, R.; SUNDARARAJAN, B.; BALA SRINIVASAN, P. Optimization of process parameters for deposition of Stellite on $45 \mathrm{CrSi} 93$ steel by plasma transferred arc technique. Disponível em: $<$ http:// www.sciencedirect.com> Acesso em: Jan. 2009.

[11] VERGARA, V. M.; DUTRA, J. C.; D'OlIVEIRA, A.S.C.M.. Cavitation erosion resistance of deposits processed by plasma transferred arc welding. Disponível em: $<$ http://www. mecanica.ufu.br/revistasi/full/full_13_01_68.pdf> Acesso em: Jan. 2009. 